\title{
Çankırı, Ilgaz Bölgesi Devrez Alt Havzası örneğinde peyzaj karakter alanlarının belirlenmesi
}

\section{Determination of landscape character areas in case of Çankırı, Ilgaz Region Devrez Lower-Basin}

\author{
Betül TÜLEK ${ }^{1}$, Meryem ATIK ${ }^{2}$
}

${ }^{1}$ Çankırı Karatekin Üniversitesi, Orman Fakültesi, Peyzaj Mimarlığı Bölümü, 18200 Çankırı

${ }^{2}$ Akdeniz Üniversitesi, Mimarlık Fakültesi, Peyzaj Mimarlığı Bölümü, 07070 Antalya

Sorumlu yazar (Corresponding author): B. Tülek, e-posta (e-mail): betulek@gmail.com

\section{MAKALE BILLGISİ}

Alınıș tarihi 24 Mayıs 2017

Düzeltilme tarihi 27 Eylül 2017

Kabul tarihi 29 Eylül 2017

\section{Anahtar Kelimeler:}

Peyzaj karakter analizi

Kümeleme analizi

Çankırı

Ilgaz

\section{$\ddot{O Z Z}$}

Peyzaj, bir arazi parçasının tanımlayıcı tüm özellikleri olarak tanımlanmıștır. Avrupa Peyzaj Sözleşmesi ile doğal, yarı doğal, kültürel peyzajların analizi, planlanması, yönetilmesi ve korunması gerekliliği belirtilmiştir. Çankırı, Ilgaz Bölgesi doğal ormanları, koruma alanları, tarihi ve kültürel varlıkları ile çok çeşitli doğal ve kültürel peyzaj alan ve tipini bir arada bulundurmaktadır. Bölge Devrez alt havzası ölçeğinde Hiyerarşik Kümeleme Analizi yöntemi kullanılarak peyzaj karakter alan ve tipleri tanımlanmış ve bu alanların peyzaj planlamadaki önemi değerlendirilerek alan kullanımına yönelik öneriler getirilmiştir. Bölgesel ölçekli peyzaj planlama ve yönetimi çalışmalarında, havza düzeyinde, bütüncül bir bakış açısıyla peyzaj karakter analizi çalışmaları entegre edilmelidir. Ilgaz Bölgesi peyzaj karakter alanları ender coğrafik özellikleri ile bölge peyzajlarının yönetimine ve korunmasında katkı sağlayacak karakterler taşımaktadır.

\section{ARTICLE INFO}

Received 24 May 2017

Received in revised form 27 September 2017 Accepted 29 September 2017

\section{Keywords:}

Landscape character assesment

Cluster analysis

Çankırı

Ilgaz

\section{ABSTRACT}

Landscape is described as an all the descriptive properties of a piece of land. The European Landscape Convention requires the analysis, planning, management and conservation of natural, semi-natural and cultural landscapes. Çankırı, Ilgaz Region has a wide range of natural and cultural landscape character types and region with natural forests, conservation areas, historical and cultural assets. In this research, the landscape characters are determined by using the Cluster Analysis method, their importance in landscape planning is evaluated and the suggestions have been developed. Landscape character analysis should be integrated in the landscape planning and management studies at the basin level, with a holistic perspective. Landscape character areas of Ilgaz with their unique geographical features provide useful tools for a better management and protection of region's landscapes.

\section{Giriş}

Peyzaj, bir alanın doğal ve kültürel özellikleri ile insan ve doğa arasındaki karşılıklı ilişkiyi ifade etmektedir. Avrupa Peyzaj Sözleşmesi'ne göre, peyzaj, “İnsanlar tarafindan algılandığı şekli ile özellikleri insan ve/veya doğal faktörlerin etkileşimi ve faaliyeti sonucu oluşan alanlar"dır (Avrupa Konseyi 2000; Resmi Gazete 2003).

Peyzaj karakteri bir peyzajı bir diğerinden ayıran, iyi veya kötü olduğu yargısına ulaştıran, belirgin, tanınabilir ve sürekliliği olan özelliklerin tümüdür. Peyzaj karakter alanı ise alan kullanımı, kültürel, tarihsel ve doğal yapı, görsel karakterleri ve özellikle de coğrafik özellikleri ile diğerlerinden ayrilan alanları ifade etmektedir (Martin 2006; Swanwick 2009; Atik ve Ortaçeşme 2010; Atik ve ark. 2015).
Peyzaj karakteri peyzajın durumunu ve kalitesini yansıtmakta ve plan kararlarına peyzajın sürdürülebilir yönetimine ve korunma ihtiyaçlarına yön vermektedir. Farina (2000)'ya göre peyzajın analizi peyzaj planlama ve yönetimi için ilk adım olup, peyzajın özelliklerinin doğru anlaşılması, dikkate alınması ve hem fiziksel hem görsel anlamda peyzaj planlama ve alan kullanım politikalarına entegre edilmesi önemlidir (Will 2005).

Peyzaj Karakter Analizi (PKA) farklı, ayırt edici, tanınabilir özelliği olan alanların, peyzajların tanımlanması, sinıflandırılması ve haritalanması çalışmalarıdır (Swanwick 2002; Swanwick 2004; Heritage Council 2004; Jellema 2009; Tudor 2014; Atik ve ark. 2015). PKA çalışmaları yerel, bölgesel 
ve ulusal ölçekteki peyzaj planlama kararları (Swanwick 2009) ve özellikle de peyzajın öne çıkan karakterlerinin korunması için önemli bilgiler sunmaktadır.

Türkiye'de peyzajın uluslararası ölçekte ele alındığı Avrupa Peyzaj Sözleşmesi (APS)'ne uygulamaya koyulmuş ve peyzajın tanımlanması, sınıflanması ve planlanmasında yönünde olumlu adımlar atılmıştır. Burada önemli bir bilimsel yaklaşım olarak PKA sonuçları İngiltere, İrlanda, Güney Kore, Yeni Zelanda, Çek Cumhuriyeti, Hollanda örneklerinde ulusal, bölgesel ve yerel ölçekte koruma planları ve alan kullanım kararları için peyzajın doğal, kültürel, görsel ve fiziksel karakterlerine temel bilgiler sunmaktadır (Swanwick 2002; Kim ve Paulet 2007; Planning Department 2008; Riezner 2008; Brabyn 2009; Atik ve Ortaçeşme 2010; Chuman ve Romportl 2010; Brown ve Brabyn 2012; Atik ve ark. 2015).

PKA uygulamaları açısından Türkiye'de Görmüş (2012) Kastamonu-Bartın Küre Dağları Milli ve korunan alanlar örneğinde peyzaj karakter analizini gerçekleştirmiş; Görmüş ve Oğuz (2013) Kapısuyu Havzası örneğinde kırsal yerleşim ve korunan alan arasındaki etkileşimin değerlendirilmesinde PKA rolünü incelemiştir. Uzun ve ark. (2015) doğal ve kültürel peyzaj envanteri temelinde "Yeşilırmak Havzası Peyzaj Atlasını hazırlanmışlardır.

$\mathrm{Bu}$ çalışmada PKA yaklaşımı Çankırı, Ilgaz Bölgesi örneğinde ve havza ölçeğinde uygulanmıştır. Ilgaz Bölgesi peyzaj karakterleri ön sınıflaması yapılmış ve ardından Hiyerarşik Kümeleme Analizi ile araştırma alanı peyzaj karakter alan ve tipleri belirlenmiş ve elde edilen sonuçlar 1şı̆̆ında Ilgaz Bölgesi peyzaj karakter alanları ile peyzaj planlama kararlarına yön verebilecek öneriler geliştirilmiştir.

\section{Materyal ve Yöntem}

\subsection{Materyal}

Araştırma alanı Ilgaz Bölgesi, Ilgaz, Kurşunlu, Tosya ve Yapraklı ilçelerinin bir bölümü ile toplam $958 \mathrm{~km}^{2}$ genişliğindeki Devrez Çayı Havzası'nı kapsamaktadır. Havza
Devrez, Bucura, Bozan, Gökçay ve Karaman olmak üzere 5 alt havzayı içermektedir. İç Anadolu Bölgesi'nin Çankırı iline bağlı olan Ilgaz, $33^{\circ} 15^{\prime}-33^{\circ} 55^{\prime}$ doğu boylamı ile $40^{\circ} 44^{\prime}-41^{\circ} 5^{\prime}$ kuzey enlemleri arasında yer almaktadır (Şekil 1).

Araştırma alanının seçiminde Ilgaz'ın doğal, kültürel, tarihsel, görsel ve estetik özellikleri ile çok yönlü peyzaj özelliklerini barındırması ve peyzaj karakter analizinin bölge peyzajlarının doğru şekilde anlaşılması, yorumlanması ve peyzaj planlama kararlarına katkı sağlayacak olması rol oynamıştır. Alana ait doğal ve kültürel özellikler, Orman ve Su İşleri Bakanlığı (2017), DSİ (2016), Çankırı İl Kültür ve Turizm Müdürlüğü (2016), Çankırı Valiliği (2013), Ilgaz Belediyesi (2014), Ilgaz Orman İşletme Şefliği (2015)' nden edinilen bilgiler ve farklı araştırıcıların benzer konular ile ilgili hazırladıkları araştırma raporları ile ortaya koyulmuştur.

\subsection{Yöntem}

Araştırmada PKA yöntemi llgaz Bölgesinde havza ölçeğinde uygulanmıştır. Washer (2002), Vogiatzakis ve ark. (2004), Hagerhall (2000), Ribeiro ve ark. (2013), Swanwick (2002), Turner (2005), Atik ve ark. (2010), Atik ve Ortaçeşme (2010), Işıklı (2010), Şahin ve ark. (2014) ile Atik ve ark. (2015) çalışmaları temel alındığı çalışmada öncelikle yükseklik, toprak özellikleri, jeoloji, Corine Alan Örtü ve bitki örtüsü olmak üzere 5 veri seti kullanılarak Çankırı, Ilgaz Bölgesi peyzaj karakterleri ön sınıflaması gerçekleştirilmiştir (Çizelge 1).

Ön sınıflamanın ardından mevcut çalışmalardan farklı olarak peyzaj karakter alan ve tipleri anlaşılmasında ve aralarındaki benzerlik, yakınlık ve uzaklıkların tespitinde Hagerhall (2000), Hoffmann-Kroll ve ark. (2003), Chuman ve Romportl (2010)'un temel alınarak hiyerarşik kümeleme analizi yapılmış, elde edilen küme veri seti liste halinde ArcGIS öznitelik tablosuna aktarılmıştır ve peyzaj karakter alan ve tipleri oluşturulmuştur. Çalışmanın yöntem akış şeması Şekil 2'de verilmiştir.

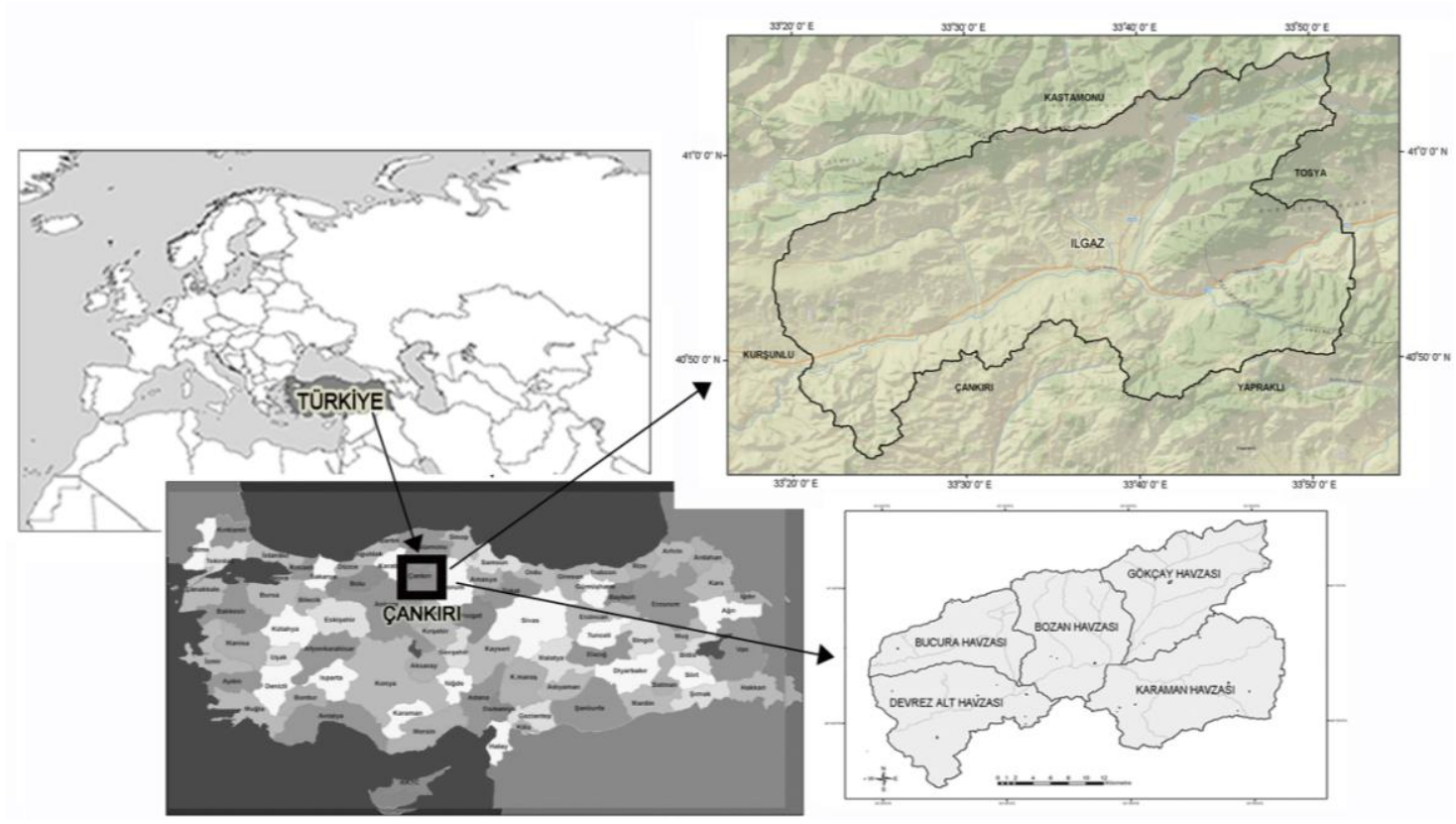

Şekil 1. Araştırma alanının konumu.

Figure1. Location of research area. 
Peyzaj karakter tiplerine ait topoğrafik özellikler, baskın arazi örtüsü ve peyzaj unsurları, nadirlik, tarihsellik, önemlilik gibi peyzajı farklı kılan görsel ve kültürel özellikler, algıyı etkileyen faktörler ve mimari stil, yerel malzeme, yapı stili, yerleşim formu, yerleşim tipi gibi peyzaj karakterinin yerinde incelenmesi gerçekleştirilmiştir. Aynı zamanda Hiyerarşik Kümeleme Analizi ile her grup ya da küme bir üst seviyedeki grup ya da kümeye ait verilerin veya veri setlerinin birbirine yakınlıklarını ve uzaklıklarını ortaya koyan (Ünlükaplan 2008) dendogramın yorumlanması sonucunda Ilgaz Bölgesi için 4 peyzaj karakter alanı tespit edilmiştir (Şekil 3). Verilerin analizinde SPSS 15.0, Coğrafi Bilgi Sistemi (CBS) ve R İstatistik Programı kullanılmıştır.

\section{Bulgular}

\section{1. Çankırı / Devrez Alt Havzası Peyzaj Karakter Alanları}

Peyzaj Karakter Alanı coğrafik özellikleri ile kendine has özellikler taşıyan alanları ifade etmektedir. Her bir peyzaj karakter alanı birden fazla peyzaj karakter tipini içerebilir özelliktedir (Swanwick 2002; Tudor 2014).

Peyzaj karakter alanlarının belirlenmesi amacıyla sayısallaştırılarak tek bir veri tabanında toplanan yükseklik, toprak özellikleri, jeoloji, Corine Alan Örtü ve bitki örtüsü

Çizelge 1. Ilgaz Bölgesi peyzaj karakterleri ön sınıflaması temel verileri.

Table 1. Preclassification of landscape characters in llgaz Region.

\begin{tabular}{|c|c|c|c|c|c|}
\hline \multirow[b]{2}{*}{$\begin{array}{l}\text { Yükseklik } \\
\text { grupları (m) }\end{array}$} & \multicolumn{2}{|c|}{ Toprak } & \multirow[b]{2}{*}{ Jeoloji } & \multirow[b]{2}{*}{ Alan Örtü Sınıfları } & \multirow[b]{2}{*}{ Bitki Örtüsü } \\
\hline & $\begin{array}{l}\text { Büyük Toprak } \\
\text { Grupları } \\
\end{array}$ & $\begin{array}{l}\text { Arazi Yetenek } \\
\text { Sinıfları } \\
\end{array}$ & & & \\
\hline $700-1150$ & -Kahverengi & I. Sinif & Alüvyon & -Ormanlar & Doğal Bitki Örtüsü \\
\hline $1150-1550$ & topraklar & II. Sinıf & Lütesiyen & -Doğal çayırlıklar & Orman vejetasyonu \\
\hline $1550-1900$ & -Kahverengi orman & III. Sinif & Malm & -Orman açıklığı ve & Herdemyeşil \\
\hline $1900-2250$ & topraklar1 & IV. Sinif & Senomaniyen & çalılıklar & Karaçam \\
\hline \multirow[t]{15}{*}{$2250-2600$} & -Kestanerengi & VI. Sinıf & Kampaniyen & -Tarım alanları & Sarıçam \\
\hline & topraklar & VII. Sinıf & Maestrihtiyen & -Kırsal yerleşimler & Göknar \\
\hline & -Kırmızımsı & VIII. Sinif & Miyosen & -Ilgaz yerleşim & Ardıç \\
\hline & kahverengi & & Oligosen & merkezi & Yaprak Döken \\
\hline & topraklar & & Pliyosen & -Madencilik & Kavak Ağaçlandırma Alanı \\
\hline & -Alüvyal topraklar & & Triyas & -Karayolu & Yaprak Döken Türler Ağırlıklı Karışık \\
\hline & -Kolüvyal topraklar & & & -Gö1/ göletler & Ormanlar \\
\hline & -Kireçsiz kahverengi & & & -Akarsular/dereler & Meşe Toplulukları \\
\hline & orman toprakları & & & & Kültürel Bitki Örtüsü \\
\hline & & & & & Tarım alanları \\
\hline & & & & & Yerleşim alanları \\
\hline & & & & & Diğer \\
\hline & & & & & Orman açıklığı \\
\hline & & & & & Dereler \\
\hline & & & & & Maden Ocağı \\
\hline
\end{tabular}

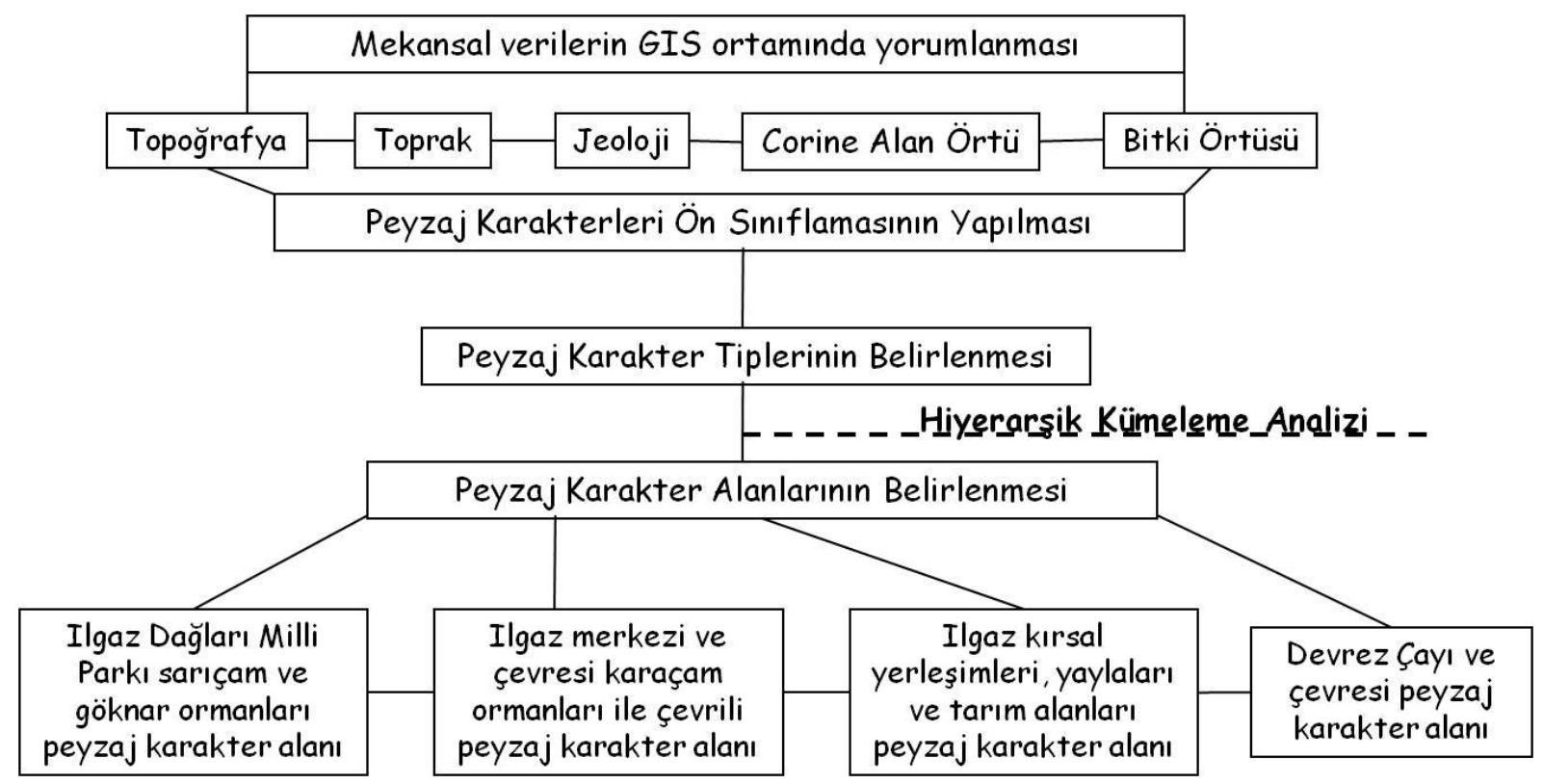

Şekil 2. Yöntem akış şeması.

Figure 2. Flow chart of the study. 
bilgilerinin Coğrafi Bilgi Sistemi (CBS) yardımıyla çakıştırılmasıyla elde edilen ve ortak özellikler taşıyan 2760 veriye R paket programları kullanılarak Hiyerarşik Kümeleme Analizi uygulanmıştır. Peyzaj karakterlerine ait toplam küme sayıs1 eğrisi ve dendogramın yorumlanması sonucunda veri seti içinde değişkenleri \% 71'ini oranında temsil eden ve benzer karakterlere sahip 20 Peyzaj Karakter Tipi olduğu belirlenmiştir (Tülek 2017). Yapılan arazi gözlemleri ve peyzaj karakterlerine ait dendogramın yorumlanması ile Ilgaz Bölgesi için toplam 4 peyzaj karakter alanı tespit edilmiştir.

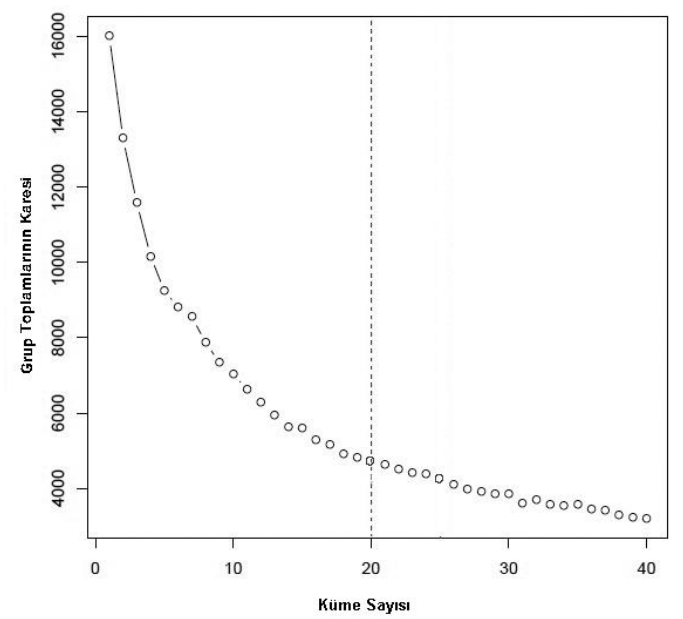

Şekil 3. Peyzaj karakterine ait toplam küme sayısı eğrisi ve dendogram.
PKA çalı̧̧ması sonucunda coğrafik olarak bölgeye özgü karakterler sergileyen ve kendine has ismini taşıyan peyzaj karakter alanları Ilgaz Dağları Milli Parkı Sarıçam ve Göknar Ormanlarl Peyzaj Karakter Alanı, Ilgaz Merkezi ve Çevresi Karaçam Ormanlarıla Çevrili Peyzaj Karakter Alanı, Ilgaz Kırsal Yerleşimleri, Yaylaları ve Tarım Alanları Peyzaj Karakter Alanı ve Devrez Çayı ve Çevresi Peyzaj Karakter Alanları olarak tanımlanmıştır (Şekil 4).

Figure 3. Screen plot of total number of clusters and dendogram of landscape characters.

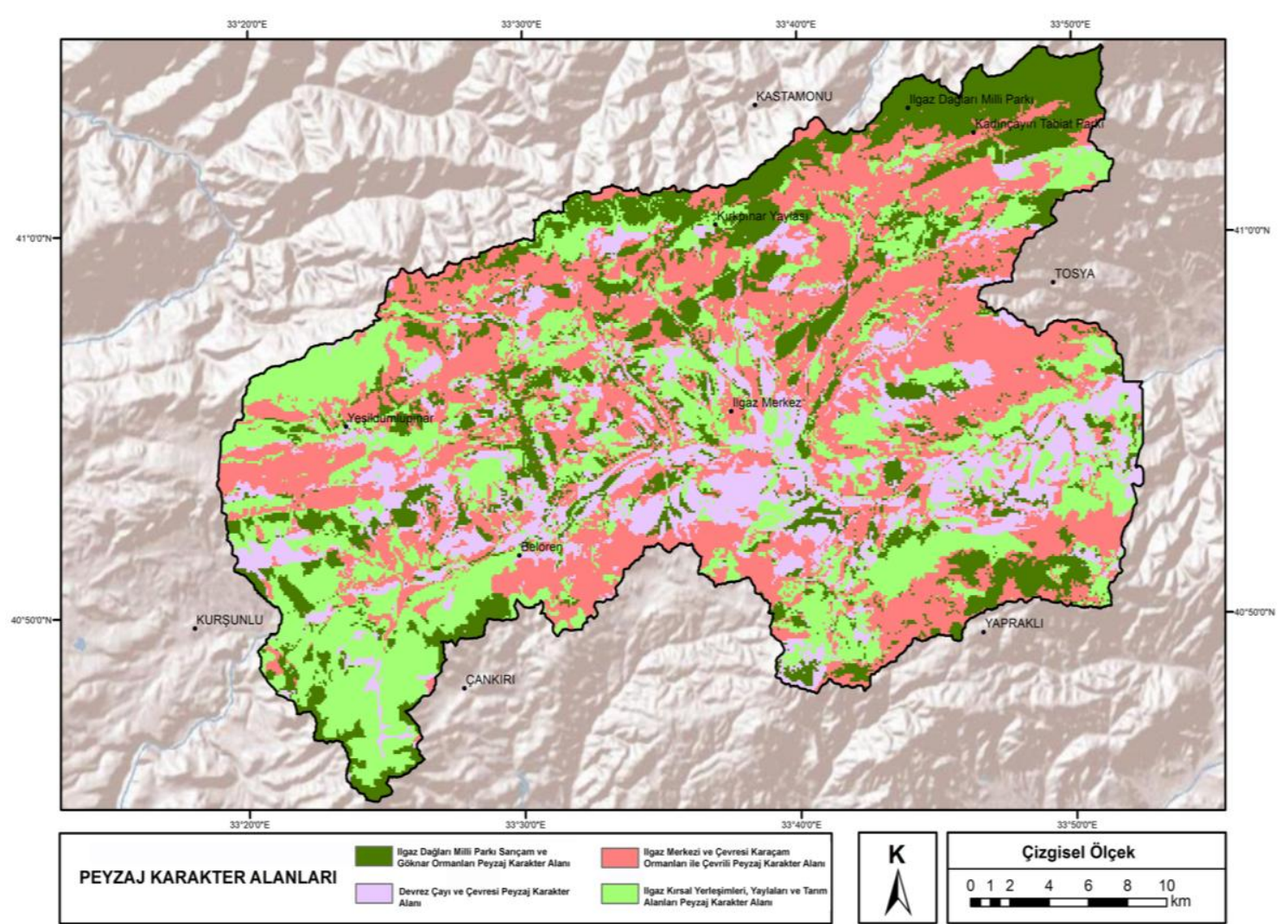

Şekil 4. Ilgaz Bölgesi peyzaj karakter alanları.

Figure. 4. Landscape character areas in llgaz Region. 


\subsubsection{Ilgaz Dağları Milli Parkı sarıçam ve göknar ormanları peyzaj karakter alanı}

Ilgaz Bölgesi'nin 700-2545 m arasında değişmekte olan topoğrafyası içinde yer alan Ilgaz Dağları Milli Parkı sarıçam ve göknar ormanları peyzaj karakter alanı Karaçam (Pinus nigra subsp. pallasiana), Sarıçam (Pinus sylvestris L.), Uludağ Göknarı (Abies nordmanniana subsp. Bornmulleriana Mattf.), Sapsız Meşe (Quercus petraea), Saplı Meșe (Quercus robur), Doğu Kayını (Fagus orientalis L.), Boylu Ardıç (Juniperus exelsa) ve Doğu Gürgeni (Carpinus orientalis) bitki türleri ile karakterize edilmektedir (Avc1 1998). Bölgenin kuzeydoğusundaki dağlık ve tepelik kesimlerde yer alan karakter alanı Ilgaz Dağı Yaban Hayatı Geliştirme Sahası, Kadınçayırı Tabiat Parkı, Yıldıztepe ve Kırkpınar göleti ve yaylalarını kapsamaktadır. Üst kesimlerde ve 1150-2545 m aralığında önemli bitki ve yaban hayatı türleri ekolojik olarak peyzaj çeşitliliğini desteklemektedir (Şekil 5).

\subsubsection{Ilgaz merkezi ve çevresi karaçam ormanları ile çevrili peyzaj karakter alanı}

Homojen bir peyzaj çeşitliliğinin gözlendiği Ilgaz merkezi ve çevresi karaçam ormanları ile çevrili peyzaj karakter alanı ovalardaki tarım arazileri, ağaç kümeleri, ağaç koridorları, doğal ve kültürel bitki kompozisyonları ile öne çıkmaktadır. Ilgaz merkezin kentsel nitelik taşıdığ 1 alanda köyler toplu yerleşim formu ile çoğunlukla dar vadiler üzerinde kurulmuşlardır. Akarsular boyunca gözlenen ve ağaç ve çalılardan oluşan bitki koridorları yüzey drenajı sağlamaları yanında arazinin mülkiyet durumunu da tanımlamaktadırlar. Karakter alanı çok sayıda kültürel ve tarihi değeri de bünyesinde barındırmaktadır. Cendere köyü, Salman Höyük kazılarına göre bölgedeki ilk yerleşimin Tunç Çağı'na uzandığı ve M.Ö 1300 sıralarında Gask (Kaska) devletinin bulunduğu anlaşılmıștır. Antik dönemlerde Paphlagonia olarak anılan bölgede, Hititlerden sonra Frigya ve
Lydia ve sirasıyla Pontus Krallığı, Romalılar, Bizanslılar, Anadolu Selçuklu Devleti, Candaroğulları Beyliği ve Osmanlı Devleti'nin hüküm sürmüştür. Kurtuluş Savaşı'nda ihtiyaç duyulan insan gücü, silah ve her türlü malzeme, Ankara'ya İnebolu-Kastamonu-Çankırı güzergahı olan ve bugün önemli kültürel ve tarihi peyzaj özelliklerini üzerinde bulunduran Ilgaz, İstiklal Yolu ile sağlanmıştır (Ilgaz İmar Planı Raporu 2007).

\subsubsection{Ilgaz kırsal yerleşimleri, yaylaları ve tarım alanları peyzaj karakter alanı}

Ilgaz kırsal yerleşimleri, yaylaları ve tarım alanları peyzaj karakter alanı 1150-1900 m arasında değişen topoğrafyası ve karaçam ormanları ile 700-1550 m yüksekliklerde ise karışık yaprak döken ormanlar ve orman açıklıklarından oluşmaktadır. Karaçam ormanları özellikle dereler ve çaylar boyunca açılan koridorlarda parçalı yamalar halinde devam etmektedir. Akarsulara yakın tepelik eğimli arazilere kurulmuş 2-3 katlı yapılardan oluşan toplu kırsal yerleșimler ile çayır-mera kullanımları dikkat çekmektedir. Alanda kış mevsiminde su toplayan, yaz mevsiminde ise kuruyan çok sayıda mevsimlik göl bulunmaktadır. Yerleşimlerin çevresindeki hafif eğimli araziler ise tarım alanı olarak kullanılmaktadır (Şekil 6).

\subsubsection{Devrez Çayı ve çevresi peyzaj karakter alanı}

Devrez Çayı ve çevresi peyzaj karakter alanı başta yoğun meşe ormanları olmak üzere yüksek kesimlerde Karaçam (Pinus nigra) ve Uludağ Göknarı (Abies nordmanniana spp. bornmulleriana Mattf.) ormanlarıla çevrilidir. Alan Devrez Çayı ve çevresinde I.sınıf topraklar, 700-1550 m yüksekliklerde ise büyük oranda alüvyon topraklardan oluşmaktadır. Aynı zamanda çöküntü ovası niteliğindeki Devrez Çayı kavak, söğüt gibi türlerden oluşan bitki koridorları ile çevrelenmektedir ve çevresindeki alanlarda yoğun çeltik tarımı yapılmaktadır (Şekil 7).

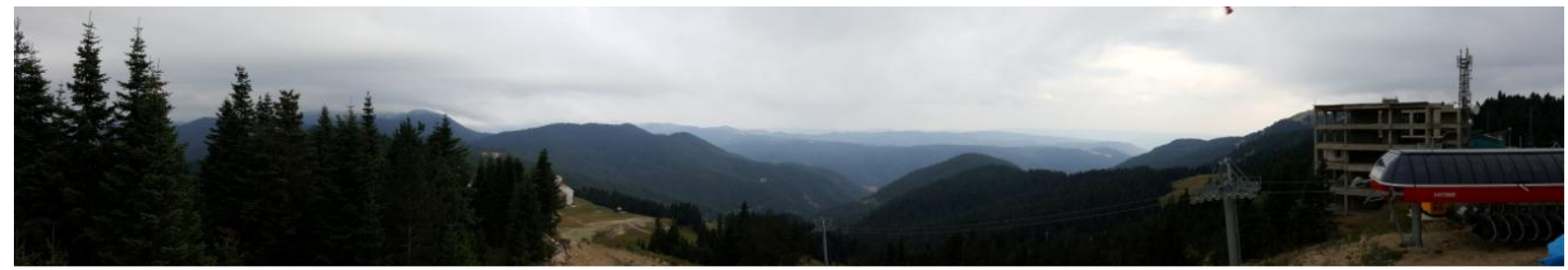

Şekil 5. Ilgaz Dağları göknar-sarıçam ormanları (Orijinal 2016).

Figure 5. Fir and yellow pine forests of the llgaz Mountains (Original 2016).

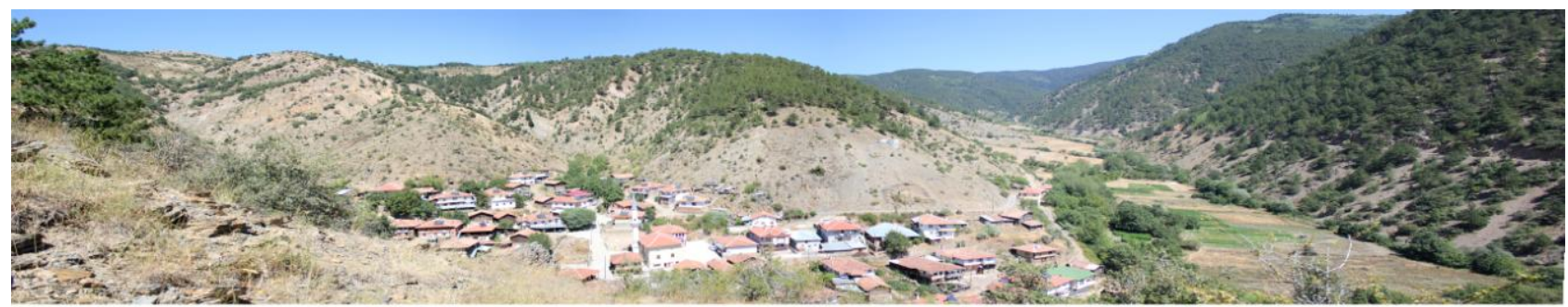

Şekil 6. Arpayeri köyü ve tarım alanları (Orijinal 2014).

Figure 6. Arpayeri village and agricultural fields (Original 2014). 

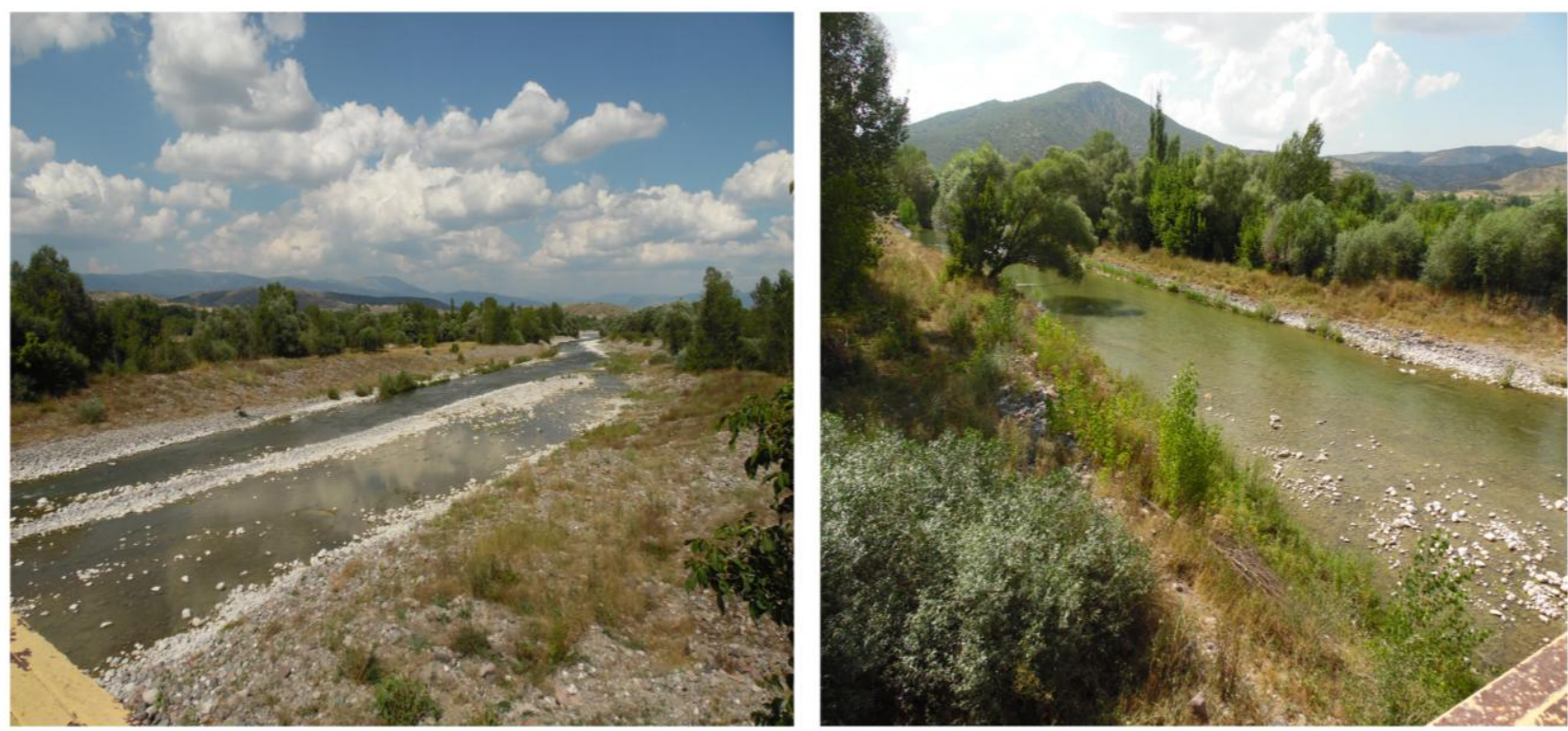

Şekil 7. Devrez Çayı (Orijinal 2015).

Figure 7. Devrez Stream (Original 2015).

\section{Tartışma ve Sonuç}

Bu çalışmada Çankırı, Ilgaz Bölgesi Devrez Alt Havzası peyzajları PKA yöntemi ile analiz edilmiş ve havzaya özgü 4 adet peyzaj karakter alanı ve 20 adet peyzaj karakter tipi tanımlanmıştır.

Peyzajları bir bütün olarak ele alan daha etkin koruma ve kullanım sağlayacak havza planlama yaklaşımlarının benimsenmesi oldukça önemlidir. Türkiye'de bölgesel ölçekteki havza planlanması ve yönetimi çalışmalarına ve ilgili politikalara peyzajin karakter analizinin entegre edilmesi ihtiyacı vardır. Dünyada ilk defa havza planlaması ve yönetimi çalışmaları, Amerika Birleşik Devletleri (ABD) ormancılık araştırmaları kapsamında 1930'lu yıllarda yapılmıştır. 1950'li y1llarda genellikle sel ve erozyon kontrolü, rehabilitasyon gibi sorun odaklı ve tek yönlü araştırmalar yapılmıştır. 1960'larda geniş kapsamlı ve bütüncül bakış açısıyla havza ölçeğinde araştırmaların yapılması gerekliliği ortaya koyulmuştur. 1970'li yıllarda ise havza ekosistem analizi geliştirilmiş ve ekosistemlerde gerçekleşen sayısız fiziksel, biyolojik ve kimyasal sürecin birbirleriyle ilişkili olduğu esası benimsenmiştir (Hornbeck ve Swank 1992). Peyzaj karakter alan ve tiplerinin belirlenmesinde peyzajlar ve su döngüsü açısından en uygun birim ve ölçek havza ölçeğidir.

Çankırı, Ilgaz Bölgesi Devrez Alt Havzası'nda yer alan Ilgaz Dağları Milli Parkı sarıçam ve göknar ormanları peyzaj karakter alanı, Ilgaz merkezi ve çevresi karaçam ormanlartyla çevrili peyzaj karakter alanı önemli doğala yakın-yarı doğal yaşam alanları olarak öne çıkmışlardır. Ilgaz merkezi ve çevresi karaçam ormanlariyla çevrili peyzaj karakter alanı ve Ilgaz kırsal yerleşimleri, yaylaları ve tarım alanları peyzaj karakter alanı tarihsel ve anitsal yönleri ile hatırlanabilirliğe sahip olup, görsel özellikleri ile de diğer tüm peyzaj karakter alanlarından ayrılmıştır. Ilgaz Dağları Milli Parkı sarıçam ve göknar ormanları peyzaj karakter alanı ekolojik olarak önemli saf Sarıçam (Pinus sylvestrist L.) ve saf Uludağ Göknarı (Abies nordmanniana spp. bornmulleriana Mattf.) ormanlarına ev sahipliği yapması, endemik bitki ve yaban hayatı türleri

barındırması açısından önemlidir ve karakterleri ile farklı bir kümelenme sergilemiştir. Ilgaz kırsal yerleşimleri, yaylaları ve tarım alanları peyzaj karakter alanında yer alan sivil mimarlık örneği niteliğindeki geleneksel konutlar kültürel karakterleri ile öne çıkmaktadır. Devrez Çayı ve çevresi peyzaj karakter alanı bölgede özellikle tarımsal üretimi destekleyen sulama, içme suyu ve balıkçılık olanaklarını sağladığı için korunması ve rehabilite edilmesi gereken alanların başında gelmektedir.

Türkiye'de PKA çalışmalarının Türkiye peyzajlarına en uygun metodolojilerden biri olduğu ve sonuçlarının planlama süreçlerine entegrasyonu konusu halen tartışılmaktadır. Türkiye'de mekânsal planlama konusundaki esaslar, ilkeler ve yetkiler, 1985 yılında yürürlüğe giren 3194 Say1lı İmar Kanunu'nda tanımlanmıştır. İmar Kanunu'nun planlama kademeleri ile ilgili 6. Maddesinde planlar, kapsadıkları alan ve amaçları açısından "Bölge Planları" ve "İmar Planları"; İmar Planları ise "Nazım İmar Planları" ve Uygulama İmar Planları" olarak kademelendirilmiş; Kanunun tanımlarla ilgili 5. Maddesinde "Çevre Düzeni Planı", "Nazım İmar Planı" ve “Uygulama İmar Planı"nın tanımı verilmiştir (Manavoğlu ve Ortaçeşme 2016).

PKA'nın uygulanabileceği en uygun planlama seviyesi, alanın doğal ve kültürel peyzaj özelliklerine ilişkin bilgilerde halkın katılımının da sağlandığı Çevre Düzeni Planlarıdır. Her şekilde alt düzeylerdeki fiziki planların tümü Çevre Düzeni planlarıyla uyumlu olmalıdır. Swanwick (2004) PKA çalışmalarının sürdürülebilir gelişme planlarının uygulanmasında yardımcı bir araç olacağına dikkati çekmiştir. PKA çalışmalarının peyzaj planlama çalışmalarında mekansal entegrasyonunun sağlanması, Türkiye'de planlama sisteminin gelişimi için önemli potansiyel niteliğindedir.

PKA çalışmalarının kapasitesi ve uzun dönem planlama kararlarının uygulanması için geçerliliği ayrıca bir soru olarak ortaya çıkmaktadır. Türkiye'de planlama sürecinde toplum katılımının olmaması ve planlama yetkinlikleri olan farklı devlet kurumları arasındaki koordinasyonun sağlanamaması ve peyzaj karakterlerinin plan girdileri olarak dikkate alınmaması belli başlı bazı sorunlardır. Bununla birlikte PKA ile peyzaj 
karakterlerinin durumunun ve zaman içindeki değişimlerinin izlenmesine 1ş1k tutacak temeller oluşturulacaktır (Atik ve ark. 2015).

Araştırma kapsamında havza ölçeğinde incelenen Ilgaz Bölgesi doğal ve kültürel kaynakları, Çevre ve Orman Bakanlığı tarafından onaylanan Sinop-Kastamonu-Çankırı Planlama Bölgesi 1/100 000 Ölçekli Çevre Düzeni Planı, Çankırı ili 2015 y1lı Çevre Durum Raporu ve 2007 yılı Ilgaz İmar Planı Raporu'nda, Ilgaz ilçe idari sınırları ölçeğinde değerlendirilmiştir. Ilgaz Bölgesi ekolojik, tarihi ve kültürel karakterleriyle öne çıkmaktadır. Bölgeye ait tarihsel karakteri güçlendiren eserlerin ve bölgeye önemli ekolojik katkılar sağlayan doğal alanların kaybedilmemesi yönünde çalışmaların yürütülmesi açısından peyzaj karakter analizi çalışmalarının özellikle havza ve alt havza ölçeğinde hazırlanacak Çevre Düzeni planlarına entegrasyonu, bölge sürdürülebilir gelişme hedeflerinin gerçekleştirilmesine katkı sağlayacaktır.

Peyzaj Mimarlığı meslek disiplini ile geliştirilen peyzaj planlama yaklaşımlarında özellikle PKA yöntemi kullanılarak peyzaja dair doğal, kültürel, görsel karakterleri ile insan, yaşadığı çevre, alan kullanımları, ürünler konusunda çalışmalar yürütülmekte ve planlamaya bütüncül bir bakış açısı getirilmektedir. Sonuçta bu çalışmada Avrupa'nın farklı ülkelerinde yaygın olarak kullanılmakta olan PKA yönteminin Türkiye'de havza ölçeğinde uygulanabilirliği incelenmiş, Ilgaz Bölgesi doğal ve kültürel peyzajları tanımlanmış, burada etkin olarak kullanılabilecek ve Türkiye'nin diğer bölgelerine uygulanabilecek bir yöntem yaklaşımının uygulanabilirliği değerlendirilmiştir.

\section{Teşekkür}

$\mathrm{Bu}$ çalışma Akdeniz Üniversitesi Bilimsel Araştırma Projeleri Birimi'nin tarafindan 2014.03.0121.013 numaralı Doktora Tez projesi kapsamında desteklenmiştir.

\section{Kaynaklar}

Atik M, Ortaçeşme V (2010) Peyzaj Karakter Analizi Yöntemi ile Antalya Side Bölgesi Kültürel Peyzajlarının Karakter Analizi. TÜBİTAK Araştırma Projesi, pp. 96.

Atik M, Mutlu Danacı H, Erdoğan R (2010) Perception of plants in ancient times and their use as motifs revealing aspects of the cultural landscape in Side, Turkey, Landscape Research, vol.35, pp.281-297.

Atik M, Işıklı RC, Ortaçeşme V, Yıldırım E (2015) Definition of landscape character areas and types in Side region, Antalya-Turkey with regard to land use planning, Land Use Policy, 44 (2015), pp. 90-100.

Avcı M (1998) Ilgaz Dağlan ve Çevresinin Bitki Coğrafyası II (Bitki örtüsünün Coğrafi Dağılışı). İstanbul Üniversitesi Edebiyat Fakültesi Coğrafya Bölümü Coğrafya Dergisi, s. 275-344.

Avrupa Konseyi (2000) Avrupa Peyzaj Sözleşmesi. http://www.coe.int/en/web/conventions/full-list//conventions/treaty/176. Erişim 30 Kasım 2016.

Brabyn L (2009) Classifying landscape character. Landscape Research 34(3): 299-321.

Brown G, Brabyn L (2012) "An analysis of the relationships between multiple values and physical landscapes at a regional scale using public participation GIS and landscape character classification”, Landscape and Urban Planning, 107(3): 317-331.

Chuman T, Romportl D (2010) Multivariate classification analysis of cultural landscapes: An example from the Czech Republic Landscape and Urban Planning, 98: 200-209.
Çankırı İl Kültür ve Turizm Müdürlüğü (2016) Çankırı İli Tescilli Taşınmaz Kültür Varlıkları Envanteri. Çankırı.

Çankırı Valiliği (2013) İlçelerimiz-Ilgaz. http://www.cankiri.gov.tr/ilcelerimiz. Erişim 14.04.2016.

DSİ (2016) Ilgaz Su Kaynakları Verileri. Türkiye Cumhuriyeti Orman ve Su İşleri Bakanlığı Devlet Su İşleri Genel Müdürlüğü 5. Bölge Müdürlüğü, Kişisel Görüşme, Ankara.

Farina A (2000) Landscape Ecology in Action. Kluwer Academic Publishers.

Görmüş S (2012) Korunan alanlarda Peyzaj Karakter Analizi: Kastamonu-Bartın Küre Dağları Milli Parkı Örneği. Ankara Üniversitesi, Fen Bilimleri Enstitüsü, Peyzaj Mimarlığı Anabilim Dalı, Doktora Tezi, s. 291.

Görmüș S, Oğuz D (2013) Kırsal Yerleșim ve Korunan Alan Arasındaki Etkileşimin Değerlendirilmesinde Peyzaj Karakter Analizinin Rolü: Kapısuyu Havzası Örneği. Tarım Bilimleri Dergisi, 19, s. 310-322.

Hagerhall CM (2000) Clustering predictors of landscape preference in the traditional Swedish cultural landscape: Prospect-refuge, mystery, age and management. Journal of Environmental Psychology, 20: 83-90.

Heritage Council (2004) Landscape Character Assessment of Country Clare, The Heritage Council, Prepared by Environmental Resources Management (ERM) in association with ERA-Maptec Ltd.

Hoffmann-Kroll R, Scheaffer D, Seibel S (2003) Landscape indicators from ecological area sampling in Germany. Agriculture Ecosystems \& Environment 98: 363-370.

Hornbeck JW, Swank WT (1992) Watershed Ecosystem Analysis as a Basis for Multiple-Use Management of Eastern Forests, Ecological Applications, 2, 3: 238-247.

Ilgaz Belediyesi (2014) Tarihi Yerleri. http://www.ilgaz.bel.tr/tarihiyerleri/. Erişim 01.02.2016.

Ilgaz İmar Planı Raporu (2007) Ilgaz (Çankırı) İlave ve Revizyon İmar Planı Açıklama Raporu. Şehir Plancısı Orhan Sarıaltun, Ilgaz Belediyesi, Ilgaz, Çankırı.

Ilgaz Orman İşletme Şefliği (2015) 1/25.000 Ölçekli Sayısal Meşcere Haritası.

Işıklı RC (2010) Antalya - Side Bölgesi Kültürel Peyzajlarının Karakter Analizi. Yüksek lisans tezi. Akdeniz Üniversitesi, Fen Bilimleri Enstitüsü, Antalya.

Jellema A, Stobbelaar DJ, Groot JCJ, Rossing WAH (2009) Landscape character assessment using region growing techniques in geographical information systems. Journal of Environmental Management 90, s. 161-174.

Kim K, Pauleit S (2007) Landscape character, biodiversity and land use planning:the case of Kwangju City Region, South Korea. Land Use Policy, 24, 1: 264-274.

Manavoğlu E, Ortaçeşme V (2015) Şehir ve Bölge Planlama Ders Notu. Yayın No: 20, Akdeniz Üniversitesi Ziraat Fakültesi Peyzaj Mimarlığı Bölümü, s. 173, Antalya.

Martin J (2006) Landscape Character Assessment (LCA) in Ireland: Baselina Audit and Evaluation. Heritage Council. ISBN 978-1906304-01-0, Dublin.

Orman ve Su İşleri Bakanlığı (2017) Ilgaz Dağı Milli Park1, http://bolge10.ormansu.gov.tr/10bolge/AnaSayfa/Korunan_Alanlari miz/milliparklar/ilgazdagimilliparki/ilgazdagimilliparkitesis.aspx?s flang=tr. Erişim 20.01.2017.

Planning Department (2008) Landscape Value Mapping of Hong Kong - Technical Report 2. Technical Report by the Government of Hong Kong SpecialAdministrative Region of the People's Republic of China, Available from:http://www.pland.gov.hk. Erişim 11 Haziran 2013.

Resmi Gazete (2003) Avrupa Peyzaj Sözleşmesinin Onaylanmasının Uygun Bulunduğuna Dair Kanun. Resmi Gazete tarih 10.06.2003, Kanun No 4881, http://www.basbakanlik.gov.tr. Erişim 25 Mayıs 2016. 
Ribeiro SC, Migliozzib A, Incerti G, Correiaa TP (2013) Placing land cover pattern preferences on the map: Bridging methodological approaches of landscape preference surveys and spatial pattern analysis, Landscape and Urban Planning 114: 53- 68.

Riezner J (2008) "Strip semibage": the landscape character type of the Jesenik area", GEOGRAFIE, 113(29): 173-182.

Swanwick C (2002) Landscape Character Assessment.Guidance for England and Scotland, Cheltenham (UK);Edinburg: The Countryside Agency; Scottish National Heritage.

Swanwick C (2004) The assessment of countryside and landscape character inEngland: an overview. In: Bishop, K., Phillips, A. (Eds.), Countryside Planning:New Approaches to Management and Conservation. Earthscan, London, pp. 109-124.

Swanwick C (2009) Society's attitudes to and preferences for land and landscape. Land Use Policy, 265: 562-575.

Şahin Ș, Perçin H, Kurum E, Uzun O, Bilgili BC (2014) Bölge - Alt Bölge (İl) Ölçeğinde Peyzaj Karakter Analizi ve Değerlendirmesi Ulusal Teknik Kılavuzu. Müssteri Kurumların T.C. İçişleri Bakanlığı, T.C. Çevre ve Şehircilik Bakanlığı ve T.C. Orman ve Su İşleri Bakanlığ 1 olduğu, T.C. Ankara Üniversitesinin Yürütücü Kuruluş olduğu ve TÜBİTAK KAMAG 1007 Programı 109G074 No'lu PEYZAJ-44 Projesi Çıktısı, Ankara.

Tudor C (2014) An Approach to Landscape Character Assessment. Natural England, ISBN: 978-78367-141-0, (2014) pp. 56.

Turner SC (2005) Devon Historic Landscape Characterisation. Devon County Council Historic Environment Service English Heritage, County Hall, Exeter, EX2 4QW.
Tülek B (2017) Çankırl, Ilgaz Bölgesi Peyzajlarının Sağladı̆̆g Faydaların Peyzaj Yapllar, Karakterleri ve Fonksiyonlarl Açısından Çok Yönlü Analizi. Akdeniz Üniversitesi Fen Bilimleri Enstitüsü, Peyzaj Mimarlığı Ana Bilim Dalı, Doktora Tezi, 176 Sayfa, 2017 Antalya.

Ünlükaplan Y (2008) Çok Değişkenli İstatistiksel Yöntemlerin Peyzaj Ekolojisi Araştırmalarında Kullanımı. Doktora Tezi. Çukurova Üniversitesi Fen Bilimleri Enstitüsü, Adana.

Uzun O, Müderissoğlu H, Demir Z, Kaya LG, Gültekin P, Gündüz S (2015) Yeşilırmak Havzası Peyzaj Atlası'nın Hazırlanması Projesi. T.C. Orman ve Su İşleri Bakanlı̆̆ı, Doğa Koruma ve Milli Parklar Genel Müdürlüğü adına AKS Planlama ve Mühendislik Ltd., Ști, Ankara.

Vogiatzakis IN, Marini A, Careddu MB, Melis MT, Griffiths GH (2004) "7th AGILE Conference on Geographic Information Science" 29 April-1May 2004, Heraklion, Greece Parallel Session 4.3"Environmental / Social Modelling".

Washer DM (2002) Landscape-indicator development: steps towards a European approach. Preecedings of Frontis workshopon the future of the European cultural landscape Wageningen, Nederlands 9-12 June 2002, Editor Rob Jongman Chapter 16, pp. 237-252.

Will H (2005) Cultural landscape history - possibilities for protection, participating institutions, and investigation methods in England. Naturschutz undLandschaftsplanung 37,11: 336-341. 